\title{
Development of a dynamic artificial neural network model of an absorption chiller and its experimental validation
}

\author{
Amine Lazrak ${ }^{\mathrm{a}, \mathrm{b}, \mathrm{c}}$, François Boudehenn ${ }^{\mathrm{b}}$, Sylvain Bonnot ${ }^{\mathrm{b}}$, Gilles Fraisse ${ }^{\mathrm{c}}$, Antoine Leconte ${ }^{\mathrm{b}}$, \\ Philippe Papillon ${ }^{\mathrm{b}}$, Bernard Souyri ${ }^{\mathrm{c}}$ \\ ${ }^{a}$ ADEME, Angers (France) \\ ${ }^{\mathrm{b}}$ CEA LITEN INES, Le Bourget du Lac, (France) \\ ${ }^{c}$ CNRS, LOCIE, Université de Savoie, Le Bourget du Lac (France)
}

\section{HIGHLIGHTS}

- A commercial absorption chiller has been tested in dynamic operating conditions on a semi-virtual test bench.

- The absorption chiller was modelled in a dynamic way using artificial neural networks.

- The model is validated using experimental data.

- The neural model predictions are very satisfactory, absolute relative errors of the transferred energy are in 0.1$6.6 \%$.

\section{ABSTRACT}

Thermally driven chillers powered by waste-heat or solar energy such as absorption chillers could be more appropriate than commercial air-conditioners that use electricity-powered compression cycles. The more the latter are installed in cities the more heat is released and thus the outdoor temperature increases. As a consequence, performance efficiency of the systems based on compression cycles will reduce. In this case those systems will consume a big deal of electricity. However, absorption chillers still face a big impediment to their commercial development for small capacity installations in buildings. The aim of this paper is to present a methodology to model and evaluate the energy performance of such systems so that users could have reliable information about the longterm performance of their systems in the wanted boundary conditions before the installation of the product. Absorption chillers behavior could be very complex and unpredictable especially when the boundary conditions are variable. The system dynamic must be then included in the model. Artificial neural networks (ANNs) have proved to be suitable to tackle such complex problems, particularly when the physical phenomena inside the system are difficult to be modelled. Reliable "black box" ANN modelling is able to identify global models of the system without any advanced knowledge of its internal operating principles. The knowledge of the system's global inputs and outputs is sufficient. The proposed methodology was applied to evaluate a commercial absorption chiller. Predictions of the ANN model developed were compared, with a satisfactory degree of precision, to two days of experimental measures. The neural model predictions are very satisfactory, absolute relative errors of the transferred energy are in $0.1-6.6 \%$.

\section{KEY-WORDS}

Thermal systems, Absorption chiller, Performance estimation, Dynamic modelling, Artificial neural networks, System testing. 


\section{Introduction}

From more than ten years now, the development of air-conditioning offers more and more comfort and safety to people. Major part (approximately 99\%) of commercial air-conditioners use electricity-powered compression cycles. This system must face a paradox: the more air-conditioners installed in a city, the more heat is released to urban atmosphere, and the more ambient air temperature increases, decreasing the performance efficiency of airconditioners and increasing the cooling load of building [1]. In fine, peak electricity demand for cooling must be tripled [2]. According to Pons et al. [1], part of the solution could be the use of thermally driven chillers powered by waste-heat or solar energy.

The major part of thermally driven chillers available on the market is absorption chiller. The basic physical process consists of at least two chemical components, one of them serving as the refrigerant and the other as the sorbent. The operation of such systems is well documented and is not described here [3]. Main advantages of this technology are the continuous thermodynamic cycle and the high thermal coefficient of performance $\left(\mathrm{COP}_{\mathrm{th}}\right)$, compared to adsorption chiller.

Absorption chillers are available on the market in a wide range of capacities and designed for different applications. However, only very few systems are available in a range below $100 \mathrm{~kW}$ of cooling capacity. $75 \%$ of these systems are single effect absorption chillers [4]. Absorption chillers behavior is highly dependent on the climatic conditions and building quality (i.e. on the boundary conditions) [5]. This is why systems could have poor energy performance in some environments. For this reason it becomes necessary that users could have reliable information about the long-term performance of the system in the wanted boundary conditions. This requires reliable and faithful models of absorption chillers under reals conditions.

Two types of models can be used to predict behavior and performances of absorption chillers: physical and empirical ones. Physical models describe all the thermodynamic cycle of the absorption chiller, heat exchangers performances and compute then heating and cooling capacity and temperatures of external fluids. On the contrary simplified models only focused on external fluids computing temperatures and power by a set of non-physical equations fitted with experimental data. Examples of those types of models are well studied and compared in steady states conditions in [6] and [7].

Among simplified models, Artificial Neural Networks (ANNs) seems to be the most powerful mathematic tool to solve this modelling problem. In fact, it was shown that ANNs are universal function approximators [8], so they can be used to approximate the system function. ANNs were applied successfully to solve complex, non-linear, dynamic and multivariable problems. They tolerate errors, imprecisions and missing data too [9]. ANNs were extensively used during the last decade and have been especially used to solve prediction modelling problems in renewable energy thermal systems [10], [11], [12], [13], [14], [15]. In the following are presented selected studies that focus on modelling absorption chiller systems:

- In [16] authors developed an ANN based model of an adsorption chiller. The ANN has 6 inputs (3 inlet temperatures and 3 flow rates) and 3 outputs ( 3 outlet temperatures). The model developed is able to predict with a high accuracy, error less than $2^{\circ} \mathrm{C}$, the output temperatures. However, because it was trained using a quasi-steady state database, the ANN cannot predict the short-term behavior of the system;

- In [17] (another similar study is presented in [18] as well) authors developed an ANN based model of a solar-driven absorption chiller. The model developed was able to predict with a low error both the $\mathrm{COP}_{\text {th }}$ and the system cooling capacity. For this study only 5 inputs were relevant to model the whole system e.g. the inlet and outlet temperatures of the evaporator and generator, and the average temperature of the hot storage tank. The inputs of the modelling configuration used are not suitable to evaluate the performance of an absorption chiller when only inlet temperatures and flow rates are available; 
- In [19] authors modelled a double effect absorption chiller in steady state using neural networks. The model was validated using experimental data of about 250 samples. The used ANN predicted the performance of the absorption chiller quite accurately ( $\mathrm{R}^{2}$ greater than 0.99$)$;

- In [20] authors have developed a control system based on an inverse ANN model. The static ANN model, which is an analytical function, leads to a short computing time and as a consequence make this methodology suitable for the on-line control of absorption cooling systems.

Further studies where static ANNs were used to model or optimize absorption chillers could be consulted in [21], [22], [23] and [24].

The presented studies focus only on steady or quasi-steady state behavior of the system and the modelling configuration used in some of them cannot be helpful to predict the long term absorption chiller energy performance. Dynamic simulation plays a very important role in the description of the real performance of an energy conversion system, especially during the activation stage or part-load operation. Such a problem is extremely relevant for absorption chillers, where the high mass of the internal components and the accumulation of the fluids inside the vessels usually make the transient period longer than for mechanical compression chillers [25]. The carried literature shows that there is a need of a complete method to model absorption chillers in order to predict their energy performance. The current work presents a methodology to model absorption chillers in a dynamic way. Indeed, the proposed method does not assume any prior knowledge about the system to be modelled or its components. This makes the method generic and more relevant for a future tool to evaluate absorption chillers energy performance within the framework of a certification context. This methodology is based on a short dynamic test and the identification of a "black box" dynamic model of the system using ANN.

\section{The absorption chiller}

The absorption chiller used in this study is a single effect water-lithium bromide chiller manufactured by the German company EAW with a nominal cooling capacity of $15 \mathrm{~kW}$. The nominal thermal COP specified by the manufacturer [26] is 0.71 . The hydraulic specifications of the chiller are presented in Table 1.

Table 1: Hydraulic specifications of the $15 \mathrm{~kW}$ cooling capacity EAW absorption chiller [26]

\begin{tabular}{llllll}
\hline \multirow{2}{*}{ EAW Wegracal SE 15 } & Capacities & $\begin{array}{l}\text { Inlet/outlet nominal } \\
\text { temperatures }\end{array}$ & $\begin{array}{l}\text { Inlet min/max } \\
\text { temperatures }\end{array}$ & $\begin{array}{l}\text { Flowrates } \\
\text { Evessure }\end{array}$ & $\begin{array}{l}\text { Preps } \\
\text { drops }\end{array}$ \\
\cline { 2 - 6 } & {$[\mathrm{kW}]$} & {$\left[{ }^{\circ} \mathrm{C}\right]$} & {$\left[{ }^{\circ} \mathrm{C}\right]$} & {$\left[\mathrm{m}^{3} / \mathrm{h}\right]$} & {$[\mathrm{mbars}]$} \\
\hline Evaporator & 15 & $17 / 11$ & $6 /-$ & 1.9 & 400 \\
\hline Generator & 21 & $90 / 80$ & $70 / 95$ & 1.8 & 400 \\
\hline Absorber-Condenser & 35 & $30 / 36$ & $25 / 40$ & 5 & 900 \\
\hline
\end{tabular}

In order to be representative, the characterization of the absorption chiller must be realized under operating conditions equivalent to those of a real system. For this, a semi virtual testing method is used. This method is based on the use of a solar cooling system model under TRNSYS, which defines at each time step the operating conditions (temperatures and flow rates) applied to the chiller. Then a dynamical test bench transforms the numerical information of the system model into real physical values at each time step.

The methodology used for the dynamical characterization of the absorption chiller is based on the dynamical study of solar combi-system (SCS) developed at INES. This protocol estimates the SCS performances on 12 days representative of the 12 months of a year [27]. Despite the fact that this methodology is difficult to transfer directly to solar cooling system, it is possible to test the solar cooling system on three representative days of the different conditions met during the summer period and corresponding to a day with a high cooling demand and a medium irradiation (day 1), a day with a high cooling demand and a high irradiation (day 2) and a day with a low cooling 
demand and a high irradiation (day 3). These three days are chosen between June the 1st and September the 30th in the Carpentras (south of France) weather data file, used for the test of the system. For each test day ( 8 hours), absorption chiller is tested and the rest of the system is simulated with TRNSYS. During the other period, the complete system, including the absorption chiller, is simulated. One advantage of this methodology is that it is able to define good initial conditions of the system (building, storage, etc.) at the beginning of the physical test of the chiller. Compiling the 3 days, is it possible to have representative experimental data of operating chiller conditions integrated into a solar cooling system.

The semi-virtual test bench consists mainly on a boiler room able to supply hot $\left(54 \mathrm{~kW}\right.$ at $\left.180^{\circ} \mathrm{C}\right)$ and cold $(150 \mathrm{~kW}$ at $-10^{\circ} \mathrm{C}$ ) water with two distribution loops, and on test modules of 25 or $50 \mathrm{~kW}$ able to reproduce the desired dynamical thermal loads within these range of temperature, Fig. 1. This test bench allows testing of various thermal systems for space heating, air conditioning and DHW preparation for different kind of applications (single or multifamily houses, small industry, small tertiary buildings). The operating conditions of each module are representative of all or part of a system and their behavior is controlled by a TRNSYS numerical model linked. With this method, a component or several components are characterized in a semi virtual environment, in fact by emulating some of the components of the system and the climatic conditions to which it is subjected. In the case of application, the climatic conditions, the solar loop, the heat rejection loop and the building are emulated.

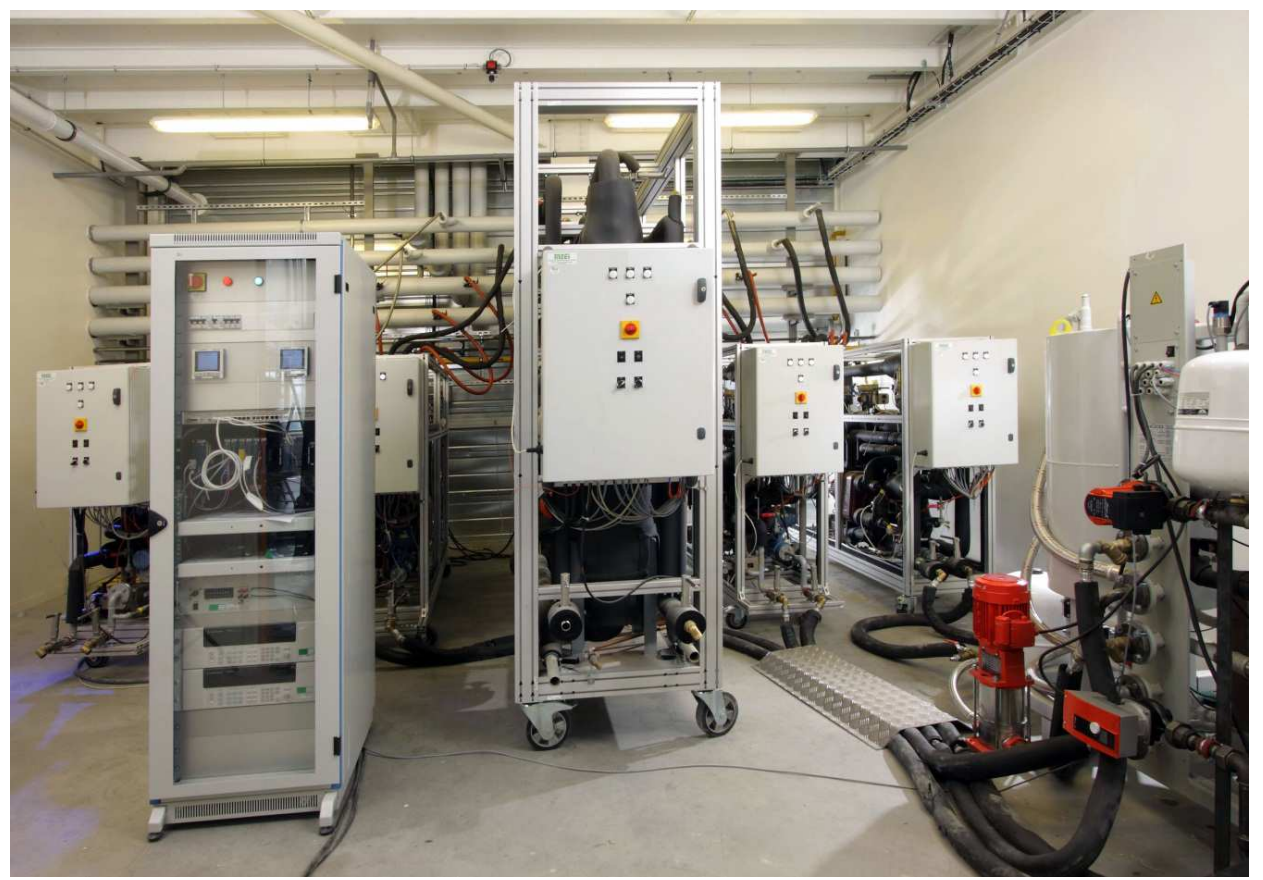

Figure 1: Picture of the EAW absorption chiller connected to the semi-virtual test bench

The test bench is equipped with temperature sensors (uncertainty of $0.1 \mathrm{~K}$ on $\mathrm{T}$ and $0.25 \mathrm{~K}$ on the $\Delta \mathrm{T}$ ) at the inlet and outlet of the tested component and with mass flow rate sensors (uncertainty of $0.2 \%$ of the measured value) on each hydraulic loop.

The TRNSYS absorption solar cooling reference system used include the following loops:

- the solar loop, used for the alimentation of the thermally driven chiller, comprised flat-plate collectors, a plate heat exchanger and a hot water storage. Using a parametric study, [5] have defined the following criteria for an optimal design of the solar loop of system : $4.5 \mathrm{~m}^{2} / \mathrm{kW} \& 55 \mathrm{l} / \mathrm{kW}$; 
- the heat rejection of the chiller is connected to a closed circuit cooling tower, designed at nominal values provided by the chiller manufacturer;

- the cold loop uses a heat exchanger like fan-coils able to transfer the cold water power provided by the chiller into cold air power introduced in the building. In order to adjust the cooling power provided by the chiller to the cooling demand of the building, the cooling power dissipated by the fan-coils into the building $\left(\mathrm{P}_{\text {cool }}\right)$ is calculated using the maximal cooling demand of the building $\left(\mathrm{P}_{\mathrm{SFH} 60}\right)$, the nominal cooling power of the chiller $\left(\mathrm{P}_{\mathrm{N}}\right)$, the effective cooling power of the fan coils $\left(\mathrm{P}_{\mathrm{fc}}\right)$ and the effectiveness of the fan coils $\left(\eta_{\mathrm{fc}}\right)$, with the following equation:

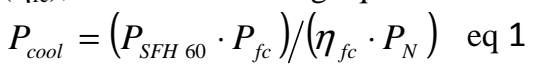

The climatic conditions and the building used for the simulation have been defined by the IEA-SHC Task 32 [28]: Carpentras (FRANCE) and a $60 \mathrm{kWh} \cdot \mathrm{m}^{-2} \cdot$ year $^{-1}$ single family house (SFH 60) with an air change rate of 0.4 volume per hour.

Two controls are used, one on the solar heat production (comparison between the solar collector temperature and the storage tank temperature with two hysteresis of $+5^{\circ} \mathrm{C}$ and of $-2^{\circ} \mathrm{C}$ ) and one on the internal temperature of the building $\left(26^{\circ} \mathrm{C}\right.$ with a hysteresis of $\left.-1^{\circ} \mathrm{C}\right)$.

The Figure 2 left gives an overview of the inlet and outlet temperature profiles on the three hydraulic loops for the 3 days compiled and the Figure 2 right presents the variation of the inlet temperature profiles for the three considered sequences: identification and validation $1 \& 2$.
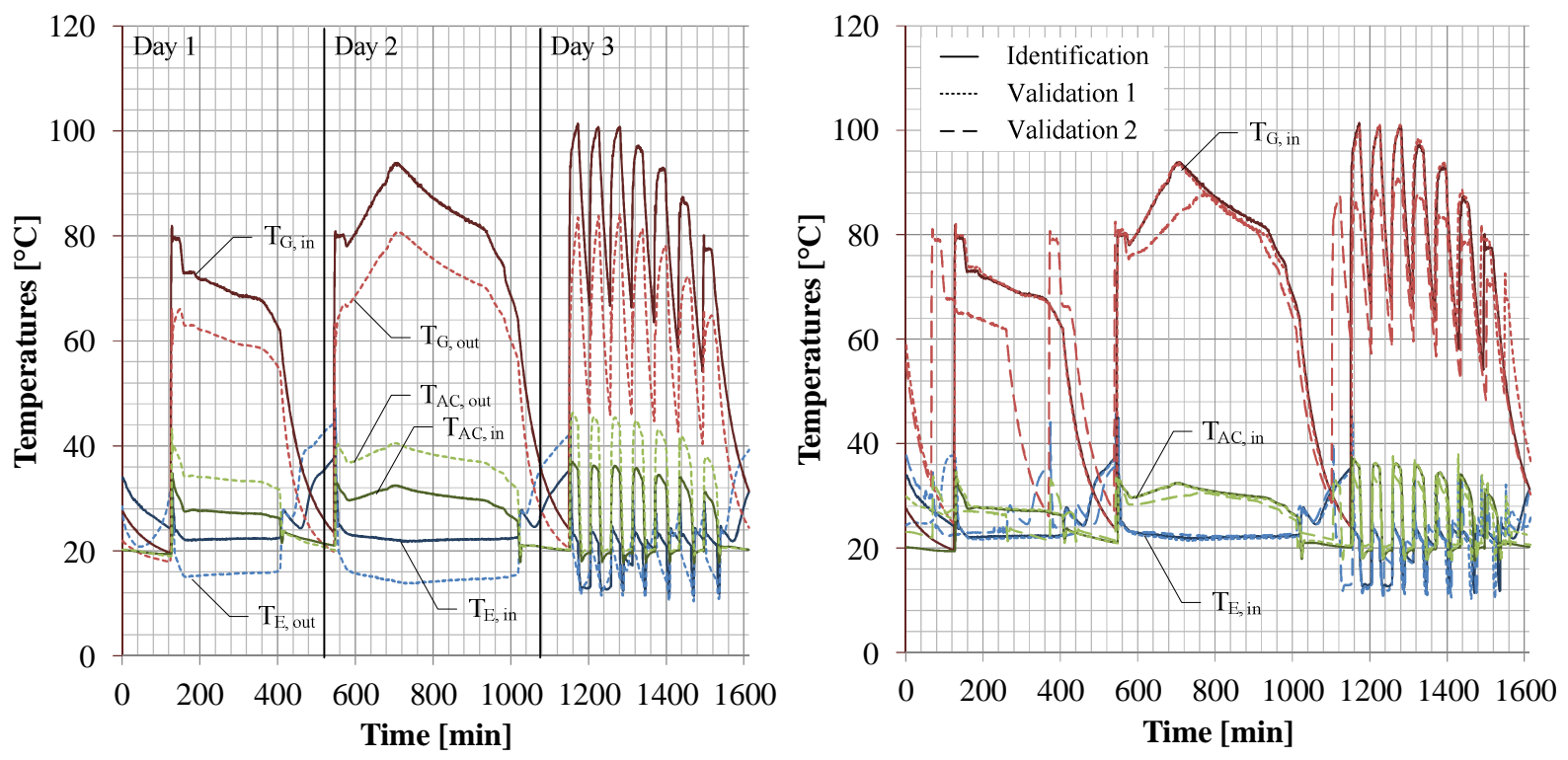

Figure 2: Operating temperatures on the three hydraulic loops (left) and inlet temperature profile variations for identification and validation test sequences (right)

On the right picture of Figure 2, the three identified days show different profiles:

- during the first day, the chiller operates during 274 minutes with a decrease of the inlet generator temperature during the day;

- during the second day, the chiller operate during 471 minutes with first an increase of the inlet generator temperature from 80 to $93.7^{\circ} \mathrm{C}$ before decreasing;

- During the day 3, due to a low cooling demand, the chiller operates in an on/off mode with a frequency close to 30 minutes for each phase. 
Changing the boundary conditions (designs of the solar loop and of the closed circuit cooling tower), it is possible to change the inlet temperatures profiles on each loop. The three considered profiles for this study are presented on the Figure xx right. The "Identification" and "Validation 1" temperature profiles are very close, contrary to the Validation 2 temperature profiles lower in terms of inlet temperature at the generator. The temperature and mass flow rate variations for each profile are described in Table 2.

Table 2: Temperature and mass flow rate variations for the different day for each profile

\begin{tabular}{llccccccccc}
\hline & & \multicolumn{3}{c}{ Identification } & \multicolumn{3}{c}{ Validation 1 } & \multicolumn{3}{c}{ Validation 2 } \\
\hline & & Average & Min. & Max. & Average & Min. & Max. & Average & Min. & Max. \\
$\mathrm{T}_{\mathrm{E}, \text { in }}$ & {$\left[{ }^{\circ} \mathrm{C}\right]$} & 22.2 & 11.4 & 45.4 & 22.0 & 10.2 & 44.8 & 22.6 & 10.6 & 45.7 \\
$\mathrm{M}_{\mathrm{E}}$ & {$[\mathrm{kg} / \mathrm{h}]$} & 1900.8 & 1891.3 & 1900.6 & 2191.2 & 1892.3 & 2192.5 & 1900.3 & 1240.9 & 2241.8 \\
$\mathrm{~T}_{\mathrm{G}, \text { in }}$ & {$\left[{ }^{\circ} \mathrm{C}\right]$} & 80.9 & 62.2 & 101.4 & 80.6 & 62.0 & 101.1 & 77.0 & 61.8 & 90.8 \\
$\mathrm{M}_{\mathrm{G}}$ & {$[\mathrm{kg} / \mathrm{h}]$} & 1900.0 & 1855.7 & 1899.9 & 1905.9 & 1895.8 & 1903.5 & 1900.0 & 1886.1 & 1904.6 \\
$\mathrm{~T}_{\mathrm{AC}, \text { in }}$ & {$\left[{ }^{\circ} \mathrm{C}\right]$} & 29.4 & 17.6 & 37.2 & 29.4 & 17.6 & 37.5 & 28.3 & 17.6 & 37.2 \\
$\mathrm{M}_{\mathrm{AC}}$ & {$[\mathrm{kg} / \mathrm{h}]$} & 5005.9 & 4986.9 & 5100.0 & 5006.1 & 4981.7 & 5100.0 & 5007.8 & 4982.3 & 5100.0 \\
\hline
\end{tabular}

During the operating mode of the absorption chiller, the thermal losses to the environment of the absorption chiller can be ignored regarding the heat transfers between the system and its boundary conditions. For this reason the ambient temperature was not considered in the model input configuration.

\section{3. The modelling approach}

179

\subsection{The ANN theory}

ANN theory is clearly presented in [29] and [30]. ANNs are parametric analytical functions whose concept takes inspiration from the human central nervous system. A neuron, the basic element of an ANN, can compute values $z_{i}$ from a weighted summation of its inputs $x_{j}$ (eq. 2). The summation coefficients $u_{j}^{l}$ are called synaptic weights. The subscript $l$ denotes the neuron number. The neural operation is presented in eq. 1 . The function $f$ is called the neural activation function $(\mathrm{AF})$.

$$
z_{l}=f\left(\Sigma z_{j=1} \omega_{j} x_{j}\right) \text { eq. } 2
$$

Inter-connected neurons constitute what is commonly called a neural network. There are several network architectures and each one is more suiTable for a specific problem than others. The most famous architecture for prediction and fitting problems is the class of the multi-layer perceptron (MLP). A MLP is a feed-forward network built of neurons, arranged in layers. It has an input layer, one or more hidden layers and an output layer. In Figure 3 a MLP, with $E$ inputs, $C$ neurons in the hidden layer and $S$ outputs, is represented. The $s^{\text {th }}$ output of the network can be obtained using eq. 3 .

$$
y_{s}=f_{s}^{S}\left(\sum_{s=1}^{C} \omega_{s}^{S} f_{c}^{C}\left(\sum_{s=1}^{E} \omega_{s}^{c} u_{s}\right)\right) \text { eq. } 3
$$

Modelling a system using an ANN means building the appropriate network architecture (hidden layers, neurons, $\mathrm{AFs})$ and identifying the different weights. 

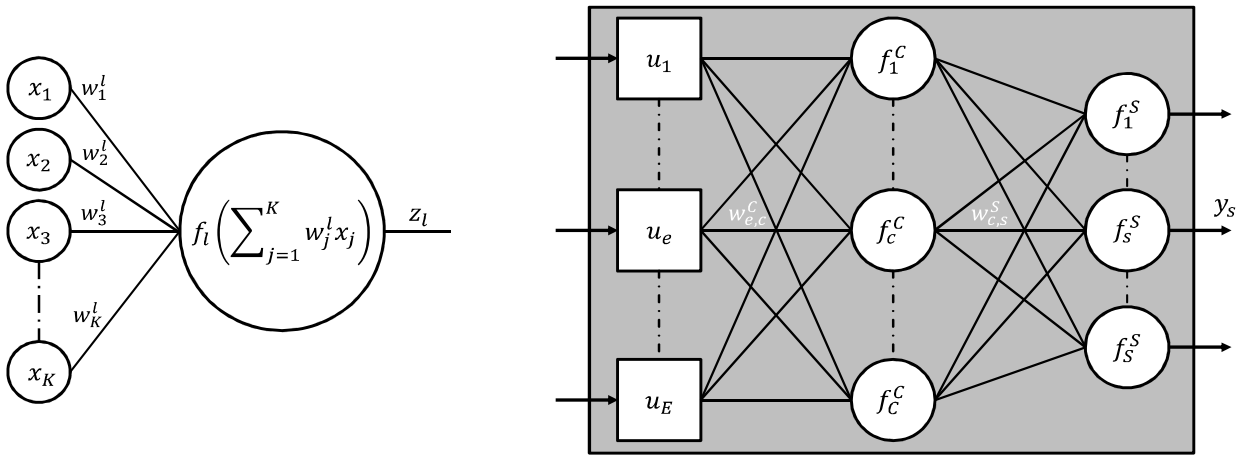

Figure. 3: Formal representation of a neuron (left), example of a neural network MLP with one hidden layer (right)

The ANN learning or training is the process of determination of an ensemble of weights so that the underlying function approximates the real system function. In fact, the objective of the training process is to minimize, for a specific ANN structure, a cost function, with respect to weights, knowing a set of data (training data).

Usually, the resulting models fit with high accuracy the learning data set (especially when a lot of neurons are used e.g. a lots of parameters). However, the model prediction precision may be very poor for unseen data (e.g. overfitting). In some cases, this means that the resulting model has learned only characteristics of the training data set and not the system behavior. In other cases probably the optimizer has been stacked in a local minimum. The learning strategies are ways to deal with those optimization algorithms and the neural network structure in order to get a model that has good generalization ability e. g. accurate estimations for unseen data.

One must be aware that the most optimization algorithms commonly used are local methods. In fact, they are valid for a region near the minimum. This is why a good way of preventing the algorithms to be stacked on a local poor minimum is to train the ANN several times with different starting points (weights initialization).

Training using Cross-Validation and Early Stopping are examples of the most famous learning strategies that are commonly used to prevent over-fitting. The both methods are based on a data set to do validation which must be taken from data available for training. Physical system tests are expensive and usually time consuming. The short time of the system test, which is long, in this study, of only one day, restricts the amount of available data for training. Therefore it is necessary to use a learning strategy that can use a restricted data set without compromising the generalization ability of the model. For this reason it is relevant to use Bayesian regularization method for the learning process. Typically, training aims to minimize the sum of squared errors (5SE) see (eq. 4) with $y$ the target data at the sequence time $t$ and $\hat{y}$ the ANN output at the same time.

$$
O b j=\frac{1}{N} \sum_{i=1}^{N}(y(t)-y(t))^{2} \text { eq. } 4
$$

Bayesian regularization modifies the objective function by adding an additional term: the sum of squares of the network weights (eq. 5) where $\boldsymbol{w}$ is a vector of parameters to be determined (synaptic weights), $\alpha$ and $\beta$ are two constant parameters calculated using a Bayesian regularization methodology [31]. By constraining the size of weights the training process produce an ANN with good generalization ability [32]. In fact, by keeping the weights small the ANN response will be smooth and so the over-fitting is supposed to be prevented. In this study the objective function minimization is done using the Levenberg-Marquardt algorithm.

$$
O b j=\alpha S S E+\beta w^{T} w \text { eq. } 5
$$

Usually, training algorithms (even if coupled to an adequate training strategy) do not necessarily guarantee the production of efficient networks based on row data. This is why it is essential to carry out some data pre-processing 
before training. By normalizing or standardizing the input and target data vectors, the ANN training will be easier and faster, and all vectors will be equally taken into account during the learning process. Equation 6 will be used to pre-treat the training data in order to fall between nor $_{\min }$ and $n r_{\max }$ (normalization bounds); $x$ represents a vector (input or output of the model) of data over time.

$$
\frac{x-x_{\min }}{x_{\max }-x_{\min }}\left(\text { nor }_{\max }-\text { nor }_{\min }\right)+\text { nor } \min \text { eq. } 6
$$

$x_{\min }$ and $x_{\max }$ represent the minimum and maximum values of each variable.

Generally ANNs do not give good results in extrapolation. One way to reduce the effect of this problem is to select carefully the normalization bounds in eq. 6 .

\subsection{The system modelling process}

Determination of the modelling input-output configuration is crucial to develop a reliable and exploitable model. The goal of this study is to develop a model able to predict the energy performance of the system (COP) and its cooling capacity. To do so, it is necessary to predict the outlet temperatures at the level of the evaporator and the generator. These two unknown variables are then used as model outputs and the other ones which are control variables e. g. inlet temperatures (condenser, evaporator and generator) and the three flow rates (condenser, evaporator and generator) are used as model inputs. In order to make the ANN learn the dynamic of the system, delayed outputs must be used as inputs too (by feeding them back). This two outlet temperatures (evaporator and generator), physically, are affected by the outlet temperature of the condenser. This is why it is relevant to add it as output of the model in order to be used as a delayed input. The resulting input-output modelling configuration is presented in Figure. 4.

The absorption chiller was tested in a dynamic way as described in section 2 .

To determine the optimal model that describes best the system dynamic behaviour, several ANN with different number of neurons (from 1 to 15) were trained. All the models contain one hidden layer and tangent hyperbolic or linear function as the AF. Three normalization bounds: $\pm 1, \pm 0.3$ and \pm 0.8 were investigated as well. As said in section 3.1 in order to prevent the minimization algorithm getting stuck in local minima each network is retrained 15 times using the Nguyen-Widrow algorithm developed in [33]. Because the true output (actual data) is available during the training of the network, the actual outputs are used instead of feeding back the predicted outputs, as shown in Figure. 4. This has the advantage to use an accurate delayed output as an input so the network will learn more 254 efficiently.

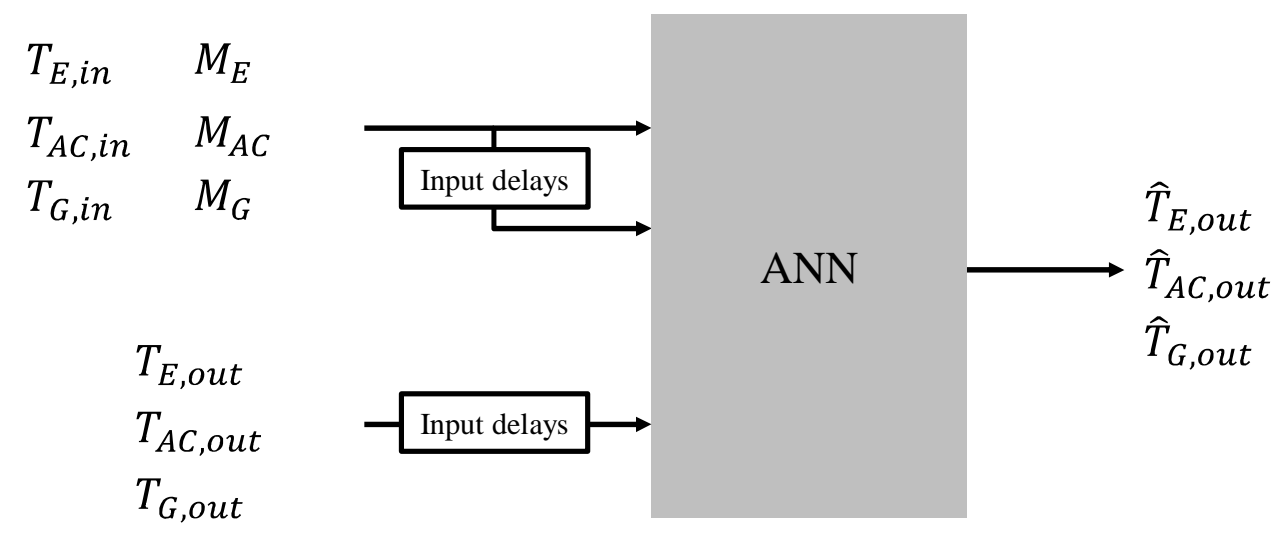

Figure. 4 :Open loop architecture 
The Bayesian information criterion (BIC) was chosen to select the most relevant network [29], [34]. It is defined by the following:

$$
B I C=\ln \frac{S S E}{N}+q \frac{\ln N}{N} \text { eq. } 7
$$

where $q$ is the number of model weights and $N$ the size of the learning data.

The BIC is calculated using only the training data and in a closed loop architecture (see Figure 5), in which only available data, e.g. inputs and the initial values of the outputs, are used to predict the outputs (long-term model simulation). The open loop architecture is used only during training. The BIC selects ANNs with a small size. This is advantageous because parsimonious ANNs have a better generalization power as stated in [35].

$$
\begin{array}{ll}
T_{E, \text { in }} & M_{E} \\
T_{A C, \text { in }} & M_{A C} \\
T_{G, \text { in }} & M_{G}
\end{array}
$$

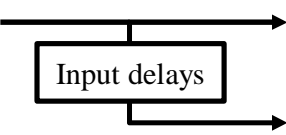

The whole training and selection process was developed in MATLAB R2012b and is represented in Figure 6 


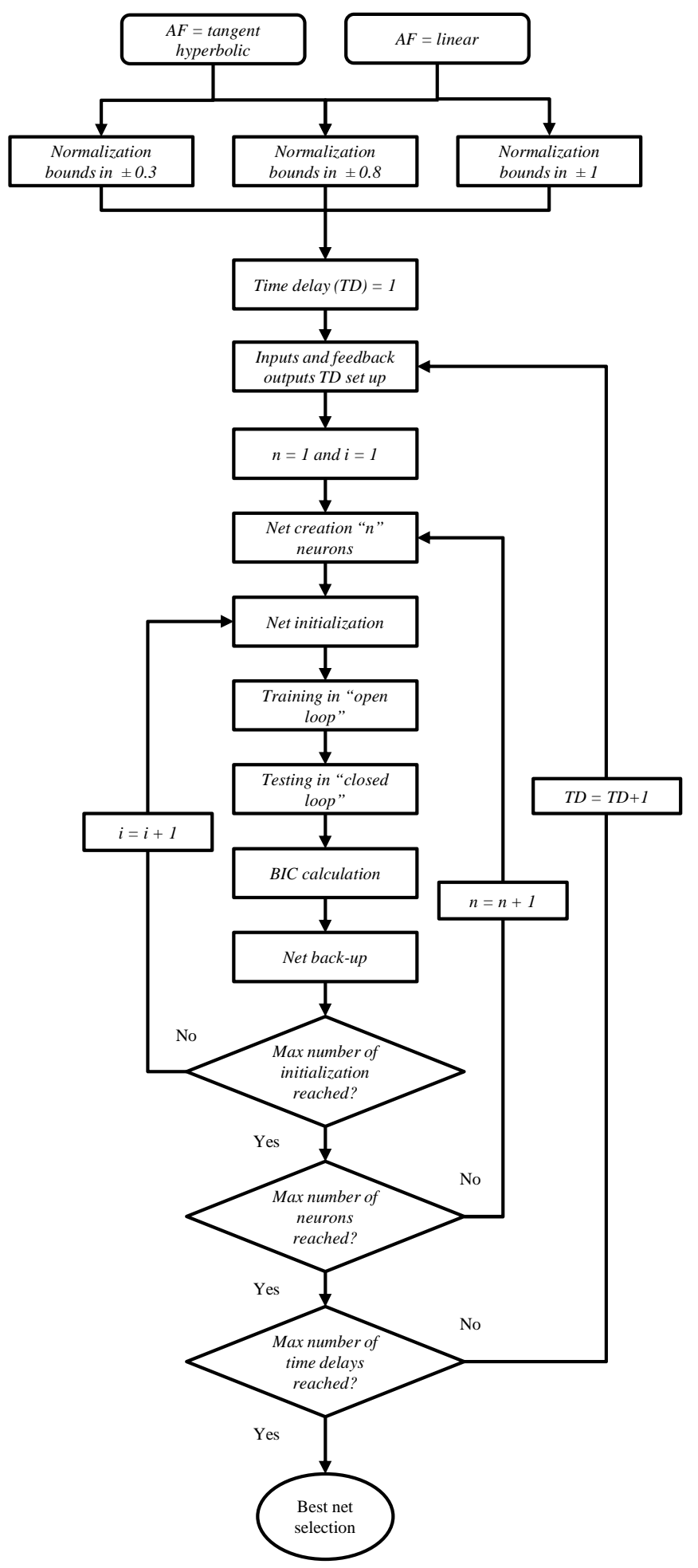




\section{Results and discussion}

\subsection{The selection of the model}

A number of $4050-15$ (number of neurons) $\times 15$ (number of initializations) $\times 3$ (number of normalization intervals) $\times 3$ (number of TD) $\times 2$ (number of AF) - models were trained. In Figure 7 and 8 the BIC values, corresponding to each created model, are visually represented. Black squares are more packed in the region where the number of neurons is lower than 10 neurons. The BIC penalizes the complexity of the model where complexity refers to the number of parameters in the model. This is in accordance with what is stated in section 3.2. It can be observed also that the penalization is more strong when the normalization interval is equal to [- 0.30 .3$]$ especially in the case of the linear AF. However, some models with a high number of parameters have a low BIC value (compared to other models with the same AF, TD and normalization interval). This observation can be explained by the fact that their SSE is quite low. The comparison between the BIC values of the ANNs selected for each model features (normalization interval, TD and AF) is given in Table 3 and 4. The best model, based on the BIC, among all the 4050 created ANNs is the model that comes from the $2^{\text {nd }}$ initialization, has 9 neurons in the hidden layer, TD equals to 1 , tangent hyperbolic AF and a normalization interval equals to [-1, 1].
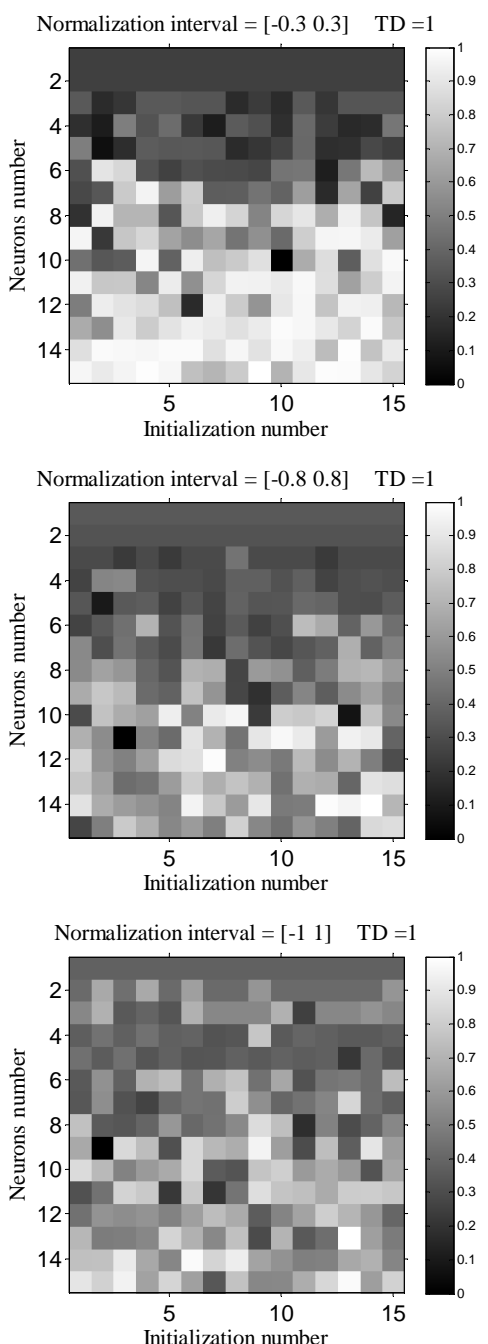
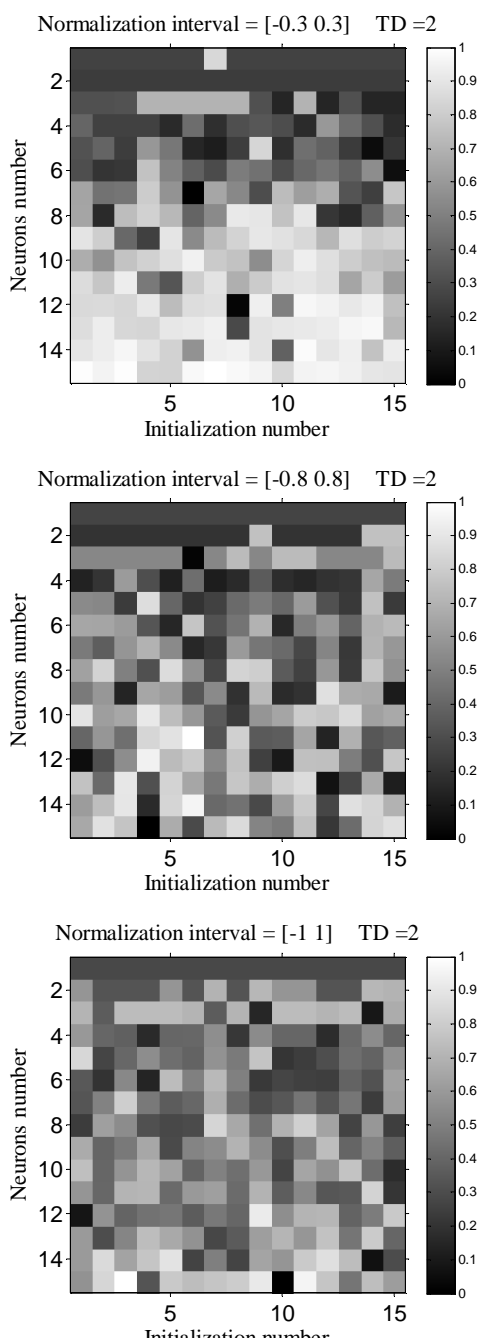
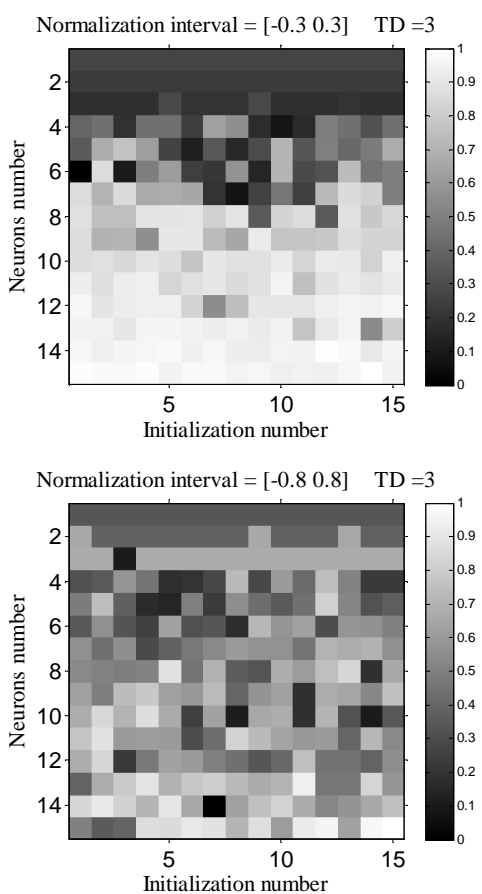

Normalization interval $=\left[\begin{array}{ll}-1 & 1\end{array}\right] \quad \mathrm{TD}=3$

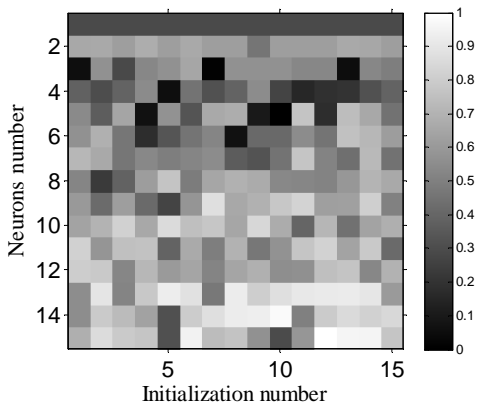

Figure. 7: Visual representation of the model selection process when the tangent hyperbolic AF is used in the output layer. BIC values 

better generalization power is.
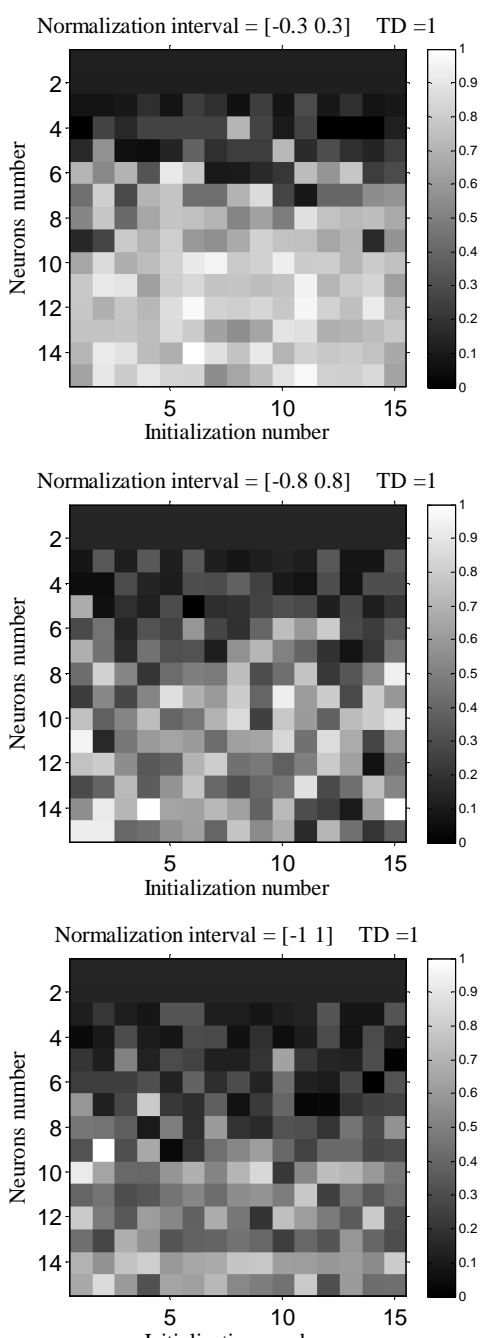
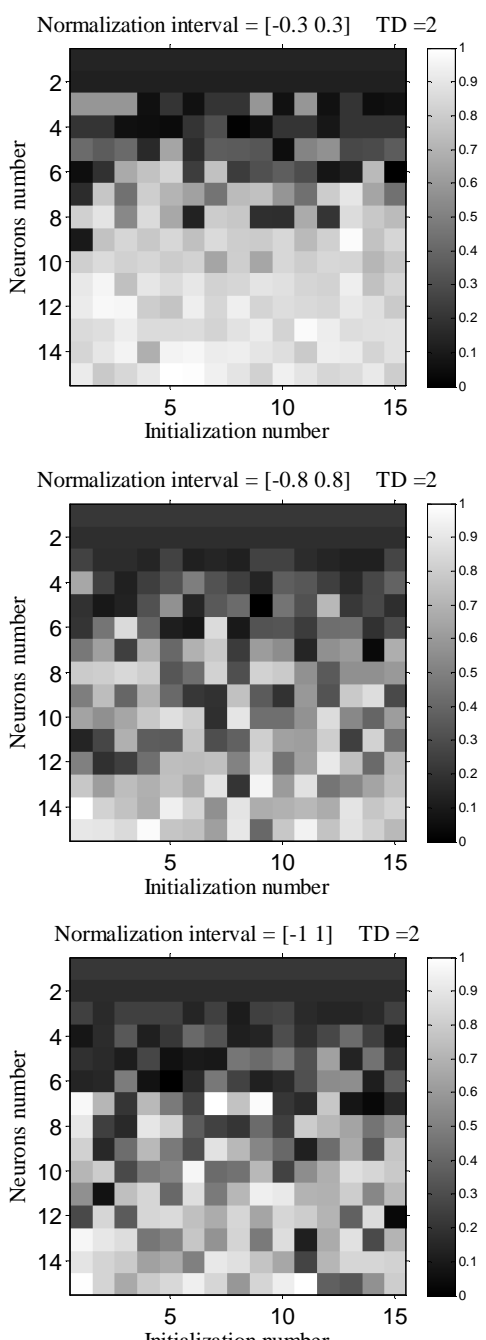
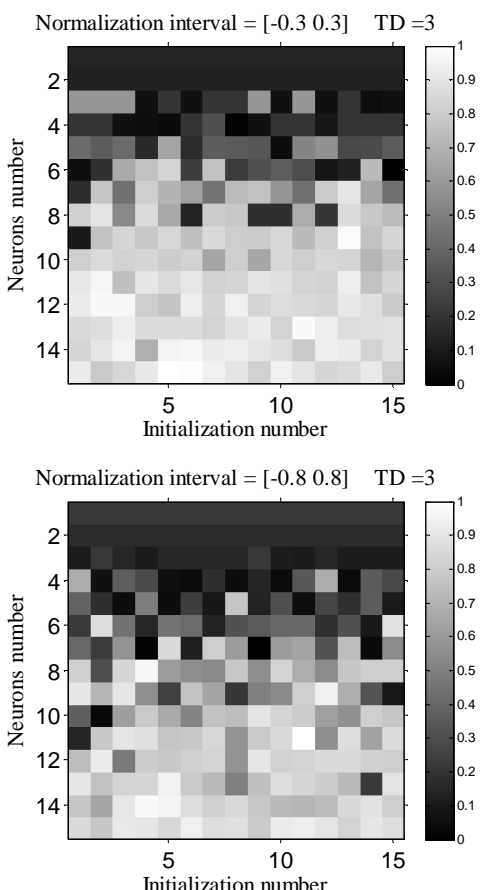

Normalization interval $=\left[\begin{array}{ll}-1 & 1\end{array}\right] \quad \mathrm{TD}=3$

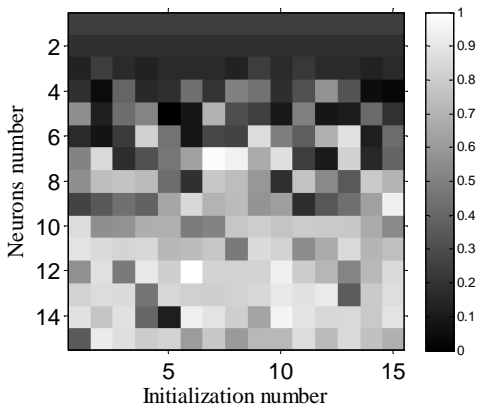

Figure. 8: Visual representation of the model selection process when the linear AF is used in the output layer. BIC values were normalized between 0 and 1 to have a better visualization. Each square represents an ANN model that has a specific number of neurons, normalization interval, TD and created after a specific initialization. The more the square is dark the low BIC is and thus the better generalization power is.

Table 3: Selected ANNs with tangent hyperbolic AF and their corresponding BIC value

\begin{tabular}{|c|c|c|c|c|}
\hline Normalization interval & $\mathrm{TD}$ & Number of neurons & Initialization number & $\mathrm{BIC}$ \\
\hline$\left[\begin{array}{ll}-0.3 & 0.3\end{array}\right]$ & 1 & 10 & 10 & 0.618 \\
\hline$\left[\begin{array}{ll}-0.3 & 0.3\end{array}\right]$ & 2 & 7 & 6 & 0.694 \\
\hline$\left[\begin{array}{ll}-0.3 & 0.3\end{array}\right]$ & 3 & 6 & 1 & 0.625 \\
\hline$\left[\begin{array}{lll}-0.8 & 0.8\end{array}\right]$ & 1 & 11 & 3 & 0.375 \\
\hline$\left[\begin{array}{ll}-0.8 & 0.8\end{array}\right]$ & 2 & 15 & 4 & 1.942 \\
\hline$\left[\begin{array}{ll}-0.8 & 0.8\end{array}\right]$ & 3 & 14 & 7 & 1.388 \\
\hline$\left[\begin{array}{ll}-1 & 1\end{array}\right]$ & 1 & 9 & 2 & 0.358 \\
\hline$\left[\begin{array}{ll}-1 & 1\end{array}\right]$ & 2 & 15 & 10 & 1.723 \\
\hline$\left[\begin{array}{ll}-1 & 1\end{array}\right]$ & 3 & 5 & 10 & 2.648 \\
\hline
\end{tabular}




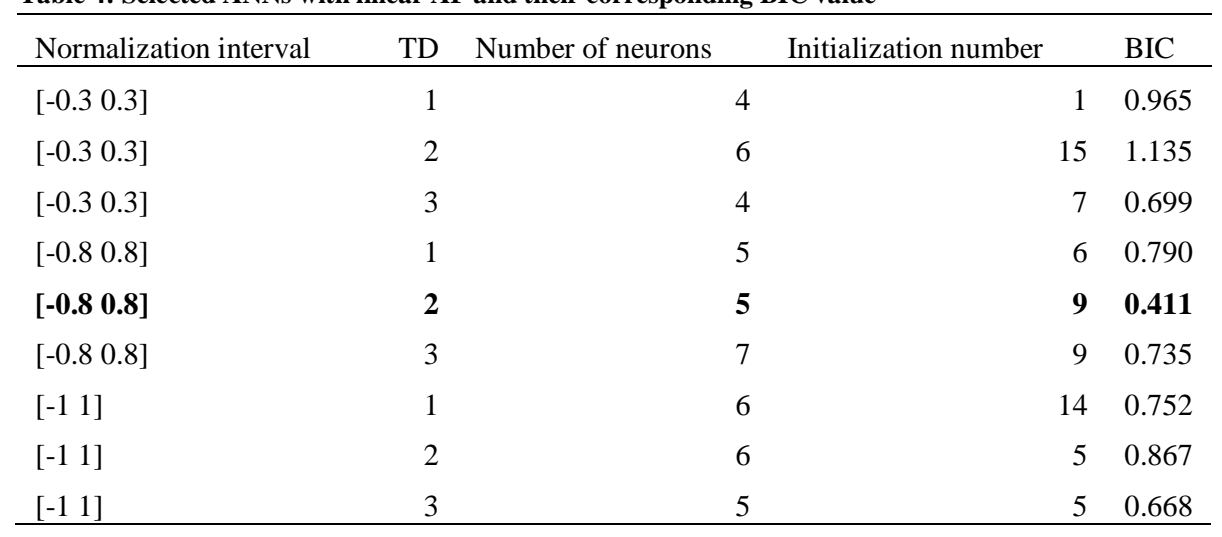

The Figure 9 presents a comparison between predictions of the selected ANN and the experimental results for the outlet temperatures of each hydraulic loop. This first comparison is based on the identification data. The absolute relative instantaneous error is calculated equation 8 , where $\hat{T}_{X}$ is the estimate of the variable $T_{X}$. This relative error is calculated only when the absorption chiller is operating e.g. when there is a flow rate in each hydraulic loop, otherwise the error is set to zero.

$$
E \eta_{X}=\frac{\left|F_{X}-T_{X}\right|}{T_{X}} \cdot 100 \% \text { eq. } 8
$$

The ANN predictions are very close to the experimental data. Outlet instantaneous temperature errors are, in the whole, less than $6 \%$ for the generator and the condenser-absorber and less than $10 \%$ for the evaporator. The learning of the latter seems to be more difficult. The mean error values are presented on the Table 5, they do not include the zero values. The mean values are less than $3 \%$ which means that the performance of the ANN training process is good. However, to effectively test the generalization ability of the artificial neural model it is necessary to use a set of experimental unseen data.

Table 5: Mean relative error values for the identification step

\begin{tabular}{lccc}
\hline & $\mathrm{T}_{\mathrm{E}, \text { out }}$ & $\mathrm{T}_{\mathrm{G}, \text { out }}$ & $\mathrm{T}_{\mathrm{AC}, \text { out }}$ \\
\hline Identification & $2.9 \%$ & $0.9 \%$ & $0.9 \%$ \\
\hline
\end{tabular}



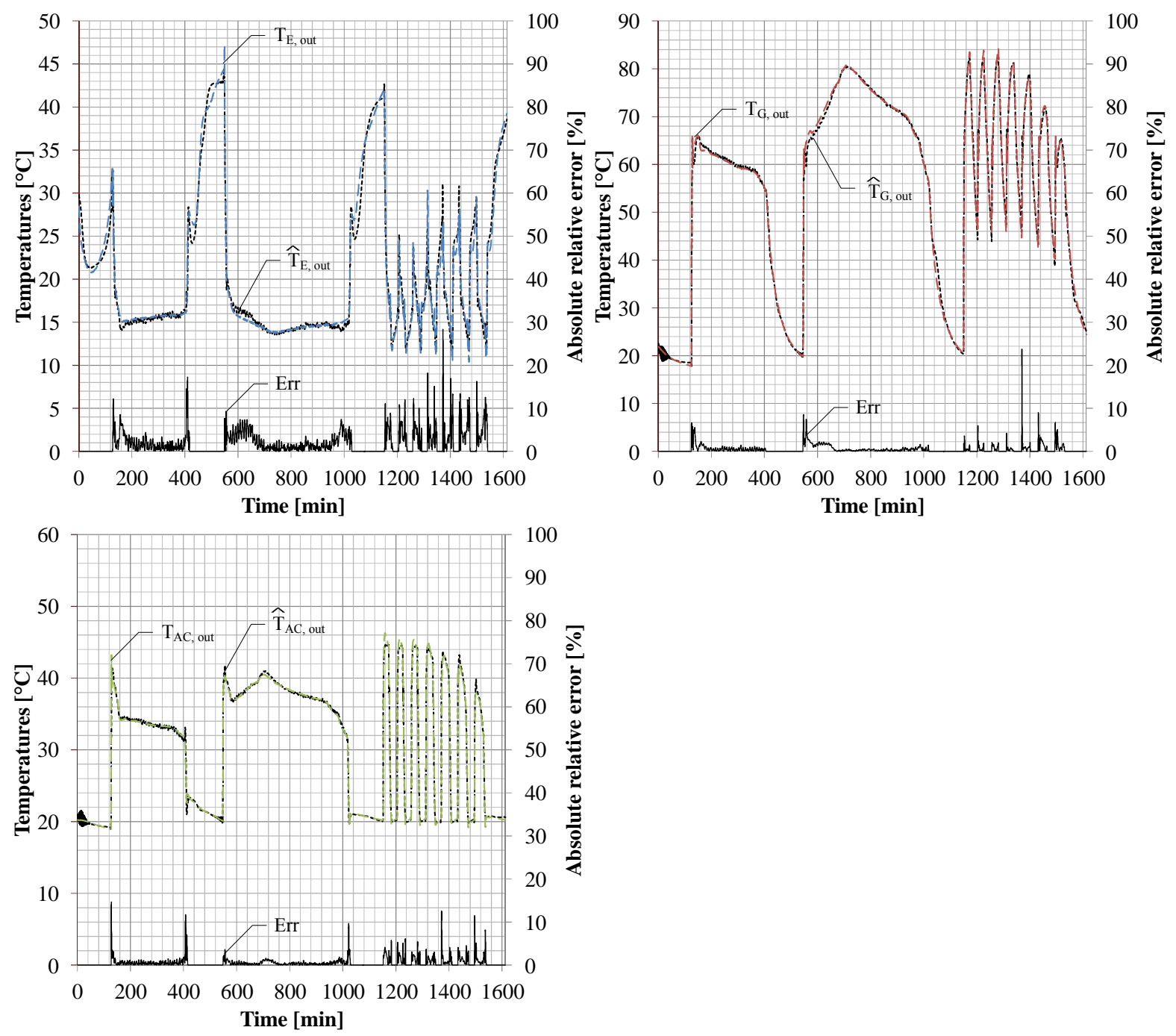

80

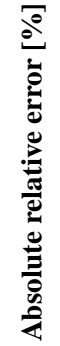

Time [min]

Figure 9: Outlet temperature comparisons between numerical and experimental results for each hydraulic loops

\subsection{Comparison with field test data}

The Figure 10 presents a comparison between the numerical (ANN predictions) and experimental results for the outlet temperatures of each hydraulic loop whereas the Figure 11 presents a comparison between the numerical and experimental results for the thermal powers of each hydraulic loop. The thermal powers are calculated by the equation 9 where $M_{X}$ is the flow rate of the considered loop and $C_{X X}$ the heat capacity of the heat-transfer fluid.

$$
P_{X}=M_{X} \cdot C p_{X} \cdot\left|T_{X_{j} \text { out }}-T_{X \text { in }}\right| \text { eq. } 9
$$

The mean error values on temperatures and thermal power are presented on the Table 6.

Table 6: Mean relative error values

\begin{tabular}{lcccccc}
\hline & $\mathrm{T}_{\mathrm{E}, \text { out }}$ & $\mathrm{P}_{\mathrm{E}}$ & $\mathrm{T}_{\mathrm{G}, \text { out }}$ & $\mathrm{P}_{\mathrm{G}}$ & $\mathrm{T}_{\mathrm{AC} \text {, out }}$ & $\mathrm{P}_{\mathrm{AC}}$ \\
\hline Validation 1 & $4.9 \%$ & $8.7 \%$ & $1.1 \%$ & $4.4 \%$ & $1.2 \%$ & $6.6 \%$ \\
Validation 2 & $5.0 \%$ & $9.3 \%$ & $2.1 \%$ & $9.3 \%$ & $1.6 \%$ & $7.9 \%$ \\
\hline
\end{tabular}


In general the ANN predicts with a good precision degree each temperature for both data sets "validation 1" and "validation 2". In fact, mean error values of the outlet temperature in each hydraulic loop are less than 5\%. As expected, the prediction of the outlet evaporator temperature by the ANN is less accurate than the two other outlet temperature variables. However, the corresponding instantaneous errors are low, still less than $10 \%$. The neural model seems reproducing with a very satisfactory precision degree the dynamic of the system, even in the on-off operating mode from $1100 \mathrm{~min}$ to $1600 \mathrm{~min}$.

The figures show that the ANN performances on the "validation 1" data are better than on the "validation 2" data. This can be explained by the fact that the "validation 1" data are close to the data used during the learning process.

Some oscillations or big differences between the ANN predictions and the test field data can be noticed in the beginning. During this period the system is off, no flow rate in the hydraulic loops, there is no heat transfer between the system and its boundary conditions except the thermal losses to the environment. In the modelling configuration of the system the ambient temperature was not taken into account, this explains why the ANN was not able to predict well the outlet temperatures in this period. However, even when the absorption chiller is off but during the test process the model gives a good estimation of the temperatures. This shows than the ANN could be able to model systems even when a potential influential variable was not included in the inputs configuration set.

335

\begin{tabular}{lccc}
\multicolumn{5}{l}{ Table 7: The absolute relative error of the transferred energy } \\
\hline & Evaporator & Absorber-Condenser & Generator \\
\hline Validation 1 & $6.6 \%$ & $2.3 \%$ & $0.2 \%$ \\
Validation 2 & $5.1 \%$ & $2.6 \%$ & $0.1 \%$ \\
\hline
\end{tabular}
when calculating the powers. operating conditions.

Table 7: The absolute relative error of the transferred energy

The mean error values for the thermal powers predictions are about $9 \%$ which is bigger than the values found for the temperature predictions. This is a mathematical amplification which depends on the value of the inlet temperature

The absolute relative errors of the transferred energy are given in the Table 7. They were calculated for all the three hydraulic loops (driving loop, heat rejection loop, chilled water loop) of the absorption chiller. Similar results, errors between $0.14 \%$ and $2.53 \%$ were found in [16] but using an adsorption chiller and in steady and quasi-steady state 

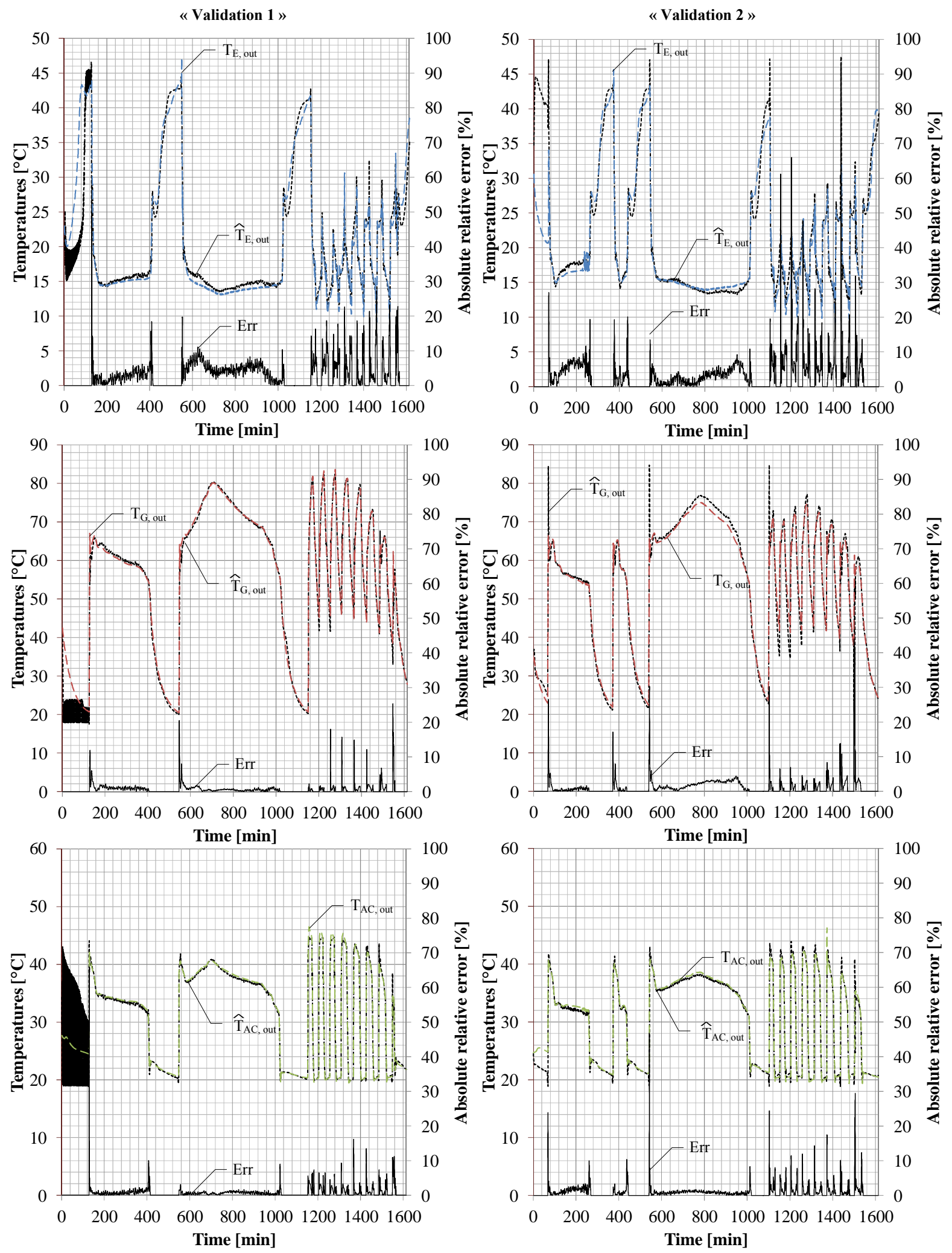

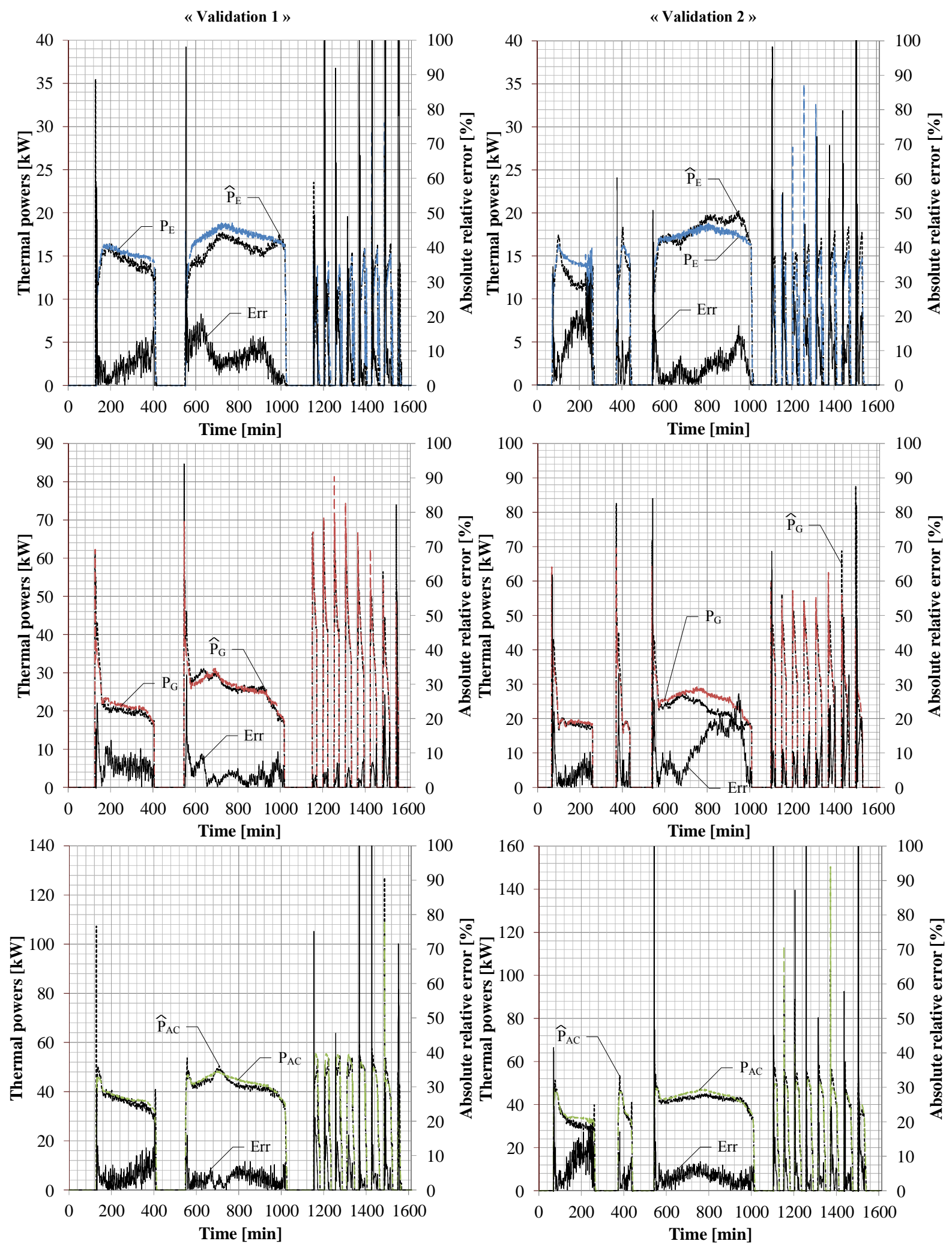

Figure 11: Thermal power comparisons between numerical and experimental results for each hydraulic loops 
In the present paper, the results of the development of a methodology to model absorption chillers for building applications are presented. This can be applied to systems as found on the market and there is no need to create a physical model of the system which could be very difficult and time consuming. The dynamic ANN models developed are able to predict, with a good level of precision, outlet temperatures and the transferred energy of all the three hydraulic loops (driving loop, heat rejection loop, and chilled water loop). In fact, the ANN generalization ability makes possible to predict the system's behaviour in various conditions (by changing the loads), different from the ones used during the ANN learning process. Absolute relative prediction errors are almost within the range of $1.1-5 \%$ for outlet temperatures and $1-6.6 \%$ for the transferred energy. The proposed approach will be helpful in the context of energy performance guarantees. Moreover, ANN simulation takes only a few seconds. This is ideal for engineers and designers to compare different solutions and select the system most suitable for a given building and location.

Although in this study the neural model was used in the simulation mode which means that predictions are done for long-term, there is a good agreement between the neural model predictions and the measured data. Usually, short term predictions are more accurate. Therefore ANN models could be used in advanced control systems (predictive control) in order to asses effectively the absorption system operation.

\section{Acknowledgments}

This study has been supported and funded by the French Agency for Environment and Energy Management (ADEME), the 490 National Institute of Nuclear Sciences and Techniques (INSTN) and the French National Research Agency (ANR) in the framework of the "ABCLIMSOL" project sponsored by Prebat program 2007.

[1] M. Pons, G. Agniès, F. Boudéhenn, P. bourdoukan, J. Castaing-Lasvignottes, G. Evola, A. Le Denn, O. Marc, N. Mazet, D. Stitou and F. Lucas, "Performance comparison of six solar-powered airconditioners operated in five places," Energy, vol. 46, no. 1, p. 471-483, 2012.

[2] M. Santamouris, N. Papanikolaou, I. Livada, I. Koronakis, C. Georgakis and A. Argiriou, "On the impact of urban climate on the energy consumption of buildings," Solar Energy, vol. 70, no. 3, pp. 201-216, 2001.

[3] H. Henning, "Solar assisted air conditioning of buildings - an overview," Applied Thermal Engineering, vol. 27, no. 10, pp. 1734-1749, 2007.

[4] «List of market available chillers compatible with solar cooling. Highlights of SHC Task 48, Quality Assurance and Support Measures for Solar Cooling,» 2012.

[5] F. Boudéhenn, M. Albaric, N. Chatagnon, J. Heinz, N. Benabdelmoumene and P. Papillon, "Dynamical studies with a semi-virtual testing approach for characterization of small scale absorption chiller," Graz, Autriche, 2010. 
[6] F. Boudéhenn, S. Bonnot, H. Demasles and A. Lazrak, "Comparison of Different Modeling Methods for a Single Effect Water-Lithium Bromide Absorption Chiller," in EUROSUN, 16-19/09/2014, Aix-LesBains - France, 2014.

[7] D. J. Swider, "A comparison of empirically based steady-state models for vapor-compression liquid chillers," Applied Thermal Engineering, vol. 23, p. 539-556, 2003.

[8] G. Cybenko, "Approximation by Superpositions of a Sigmoidal Function," Math. Control Signals Systems, vol. 2, pp. 303-314, 1989.

[9] S. A. Kalogirou, «Artificial neural networks in renewable in renewable energy systems application: a review,» Renewable and Sustainable Energy Reviews, vol. 5, pp. 373-401, 2001.

[10] S. Yilmaz et K. Atik, «Modeling of mechanical cooling system with variable cooling capacity by using artificial neural network,» Applied Thermal Engineering, vol. 27, pp. 2308-2313, 2007.

[11] M. W. Ahmad, M. Eftekhari, T. Steffen et A. M. Danjuma, «Investigating the performance of a combined solar system with heat pump for houses, » Energy and Buildings, vol. 63, pp. 138-146, 2013.

[12] F. Almonacid, C. Rus, P. Perez-Higueras et L. Hontoria, «Estimation of the energy of a PV generator using artificial neural network,» Renewable Energy, vol. 34, pp. 2743-2750, 2009.

[13] P. Vig et I. Farkas, «Neural network Modeling of thermal stratification in a solar DHW storage,» Solar Energy, vol. 84, pp. 801-806, 2010.

[14] S. Kalogirou, E. Mathioulakis et V. Belessiotis, «Artificial neural networks for the performance prediction of large solar systems, » Renewable Energy, vol. 63, pp. 90-97, 2014.

[15] A. S. Kalogirou, «Artificial neural networks and Genetic Algorithms in Energy Applications in Buildings," Advanced in building energy research, vol. 3, pp. 83-120, 2009.

[16] P. Frey, S. Fischer et H. Drück, «Artificial Neural Network modelling of sorption chillers,» Solar Energy, vol. 108, p. 525-537, 2014.

[17] S. Rosiek et F. Batlles, «Performance study of solar-assisted air-conditioning system provided with storage tanks using artificial neural networks, » International Journal of Refrigeration, vol. 34, pp. 1446-1454, 2011.

[18] S. Rosiek and F. Batlles, "Modelling a solar-assisted air-conditioning system installed in CIESOL building using an artificial neural network," Renewable Energy, vol. 35 , pp. 2894-2901, 2010.

[19] H. Manohar, R. Saravanan et S. Renganarayanan, «Modelling of steam fired double effect vapour 
absorption chiller using neural network, ") Energy Conversion and Management, vol. 47 , p. 22022210, 2006.

[20] J. Labusa, J. Hernández, J. Bruno and A. Coronas, "Inverse neural network based control strategy for absorption chillers," Renewable Energy, vol. 39, pp. 471-482, 2012.

[21] T. Chow, G. Zhang, Z. Lin et C. Song, «Global optimization of absorption chiller system by genetic algorithm and neural network,» Energy and Buildings, vol. 34, pp. 103-109, 2002.

[22] V. Congradac et F. Kulic, «Recognition of the importance of using artificial neural networks and genetic algorithm to optimize chiller operation,» Energy and Buildings, vol. 47 , p. 651-658, 2012.

[23] A. Şencan, "Performance of ammonia-water refrigeration systems using artificial neural networks," Renewable Energy, vol. 32, no. 2, p. 314-328, 2007.

[24] A. Şencan, K. A. Yakut and S. A. Kalogirou, "Thermodynamic analysis of absorption systems using artificial neural network," Renewable Energy, vol. 31, no. 1, p. 29-43, 2006.

[25] G. Evola, N. Le Pierres, F. boudéhenn and P. Papillon, " Proposal and validation of a general model for the transient simulation of single-stage $\mathrm{LiBr} /$ water absorption chillers," International Journal of Refrigeration, vol. 36 , pp. 1015-1028, 2013.

[26] "EAW, 2012. Technische Beschreibung, Absorptionskälteanlagen WEGRACAL SE 15.," [Online]. Available: http://www.eaw-energieanlagenbau.de..

[27] A. Leconte, G. Achard et P. Papillon, «Global approach test improvement using a neural network model identification to characterise solar combisystem performances," Solar Energy, vol. 86, pp. 2001-2016, 2012.

[28] R. Heimrath et M. Haller, «Project Report A2 of Subtask A: The Reference Heating System, the Template Solar System,» A Report of IEA SHC - Task 32, 2007.

[29] G. Dreyfus, Neural networks methodology and applications, Springer, 2005.

[30] M. Norgaard, O. Ravn, N. Poulsen et L. Hansen, Neural networks for modelling and control of dynamic systems, Springer, 2000.

[31] F. Forsee and M. Hagan, "Gauss-Newton approximation to Bayesian learning," in IEEE international conference on neural networks, Houston, TX, USA, 1997.

[32] Mackay, chez Proceedings of the International Joint Conference on Neural Networks, 1992.

[33] D. Nguyen et B. Widrow, «Improving the learning speed of 2-layer neural networks by choosing initial values of the adaptative weights, $\gg$ Proceeding of the International Joint Conference on Neural 
Networks, vol. 3, pp. 21-26, 1990.

[34] M. Qia and G. P. Zhangb, "An investigation of model selection criteria for neural network time series forecasting," European Journal of Operational Research, vol. 132, no. 3, p. 666-680, 2001.

[35] A. Khosravi, Nahavandi, D. Creighton and Saeid, "Quantifying uncertainties of neural network-based electricity price forecasts," Applied Energy, vol. 112, p. 120-129, 2013.

[36] W. Yaïci et E. Entchev, «Performance prediction of a solar thermal energy system using artificial neural networks," Applied Thermal Engineering, 2014.

[37] G. Cybenko, "Approximation by Superpositions of a Sigmoidal Function," Math. Control Signals Systems, vol. 2, pp. 303-314, 1989. 